\title{
Modeling a Large Air-Cooled Condenser
}

\author{
D.L. Louw ${ }^{1, *}$, C.J. Meyer ${ }^{1, * *}$, and S.J. van der Spuy ${ }^{1, * * *}$ \\ ${ }^{1}$ Department of Mechanical and Mechatronic Engineering \\ University of Stellenbosch \\ Stellenbosch, 7600
}

\begin{abstract}
.
This study reports on a modeling strategy for large Air-Cooled Condensers (ACCs). A large 64-fan ACC was modeled under various crosswind conditions that investigated the ACC's specific axial flow fan configuration. The ACC model was developed in two parts, an axial flow fan model and a heat exchanger model. The axial flow fans were modeled using an Actuator Disk Model (ADM). The heat exchangers' pressure drop was modeled using the Darcy-Forchheimer porosity model, and the Effectiveness Number of Transfer Units $(\varepsilon$-NTU) method was used to determine the air heat transfer rate. The ACC was configured using two different axial flow fans, identified in this study as the L-fan and the $\mathrm{N}$-fan. Comparatively the L-fan has a steeper fan static pressure characteristic curve than that of the $\mathrm{N}$-fan, at the cost of a greater shaft power consumption. Under normal operating conditions the average heat-topower ratios were calculated at $89.91 \mathrm{~W} / \mathrm{W}$ for the $\mathrm{L}-$ fan and $102.48 \mathrm{~W} / \mathrm{W}$ for the $\mathrm{N}$-fan. Under crosswind conditions of $9 \mathrm{~m} / \mathrm{s}$ the heat-to-power ratios of the leading edge fan-units decreased by $80.6 \%$ and $87.0 \%$ for the L-fan and $\mathrm{N}$-fan respectively. However, at the fan-units immediately downstream of the leading edge the heat-to-power ratios only decreased by $34.1 \%$ for the L-fan and $64.2 \%$ for the $\mathrm{N}$-fan.
\end{abstract}

\section{Introduction}

Thermal power generation requires the discharge of heat to complete the steam cycle [1]. Multiple coal-fired power stations operated by Eskom, such as Matimba, Medupi and Kusile, utilize air-cooled condensers (ACCs) to facilitate this heat discharge. The dependence of ACCs on airflow for heat transfer renders them sensitive to atmospheric wind conditions.

This study investigates a 64 fan-unit forced draft configuration ACC and its performance subject to various crosswind conditions. Various forced draft configuration ACCs under adverse crosswinds conditions have previously been investigated [2-5]. However, these ACCs faced limitations in terms of the nature of the axial flow fan models used $[3,4]$ and/or the size of the ACC investigated ( $\max 30$ fan-units) $[2,3,5]$.

Simplified fan models are required due to the prohibitive numerical cost of full 3dimensional fan models [6]. The actuator disk model (ADM) [7] used in this study provides

\footnotetext{
*e-mail: 17562252@sun.ac.za

**e-mail: cjmeyer@sun.ac.za

***e-mail: sjvdspuy@sun.ac.za
} 
greater accuracy than a PJM at a fraction of the computational cost of fully explicit 3D fan modeling [6].

This study investigates a traditional forced draft ACC with 64 A-frame fan-units in a $8 \times 8$ configuration. The performance of the ACC is investigated as the system is subjected to various crosswinds, which are applied in two directions, i.e. parallel and perpendicular to the streets of fan-units, and are applied at multiple reference velocities. A specific fan configuration utilising a high power fan at the front and back of the ACC is also tested as a means to improve performance under adverse crosswind.

\section{Numerical Models}

\subsection{Governing Equations}

A fluid's motion in 3-dimensions is governed by 3 principles $[8,9]$, which are the conservation of mass, the conservation of momentum given, and the conservation of energy.

The standard $k-\varepsilon$ turbulence model [10], with its canonical constants, was used in this study. The model provided greater numerical stability than the $k-\varepsilon S S T$ turbulence model.

The equations are discretized and solved numerically using the finite volume method (FVM) using the open source CFD code OpenFOAM [11]. The OpenFOAM CFD toolbox allowed for the development and integration of additional numerical models needed to model the ACC.

The OpenFOAM incompressible flow solver with the Boussinesq buoyancy model (buoyantBoussinesqSimpleFoam) is used in this study [5]. The solver uses an alternative pressure field, $p^{\prime}$, which is obtained by subtracting the hydrostatic component from the actual pressure:

$$
p^{\prime}=p_{\text {ref }}-\rho_{k} g h
$$

where $\rho_{k}$ is the Boussinesq density, $g$ is the gravitational acceleration, $h$ is the height above ground level.

The incompressible flow solver was used for its numerical stability [5]. The Boussinesq buoyancy model was used to reduce computational costs, and is valid when $\Delta \rho / \rho_{k} \ll 1$.

\subsection{Axial Flow Fan Model}

The axial flow fan is modeled using a custom actuator disk model (ADM) that uses three axially aligned disks to represent the fan being modeled [7]. The fan's inlet and outlet flow field velocities are obtained from the upstream and downstream disks. These velocities are used to calculate the unique relative flow velocities, $U_{R}$, and angles of attack, $\alpha$, at each cell in the actuator disk.

The lift and drag forces, $F_{L}$ and $F_{D}$, imparted by the fan blades are calculated for each radial segment of the fan blade using blade element theory:

$$
\begin{aligned}
F_{L} & =\frac{1}{2} \rho\left|U_{R}\right|^{2} C_{L} c \\
F_{D} & =\frac{1}{2} \rho\left|U_{R}\right|^{2} C_{D} c
\end{aligned}
$$

where $C_{L}$ and $C_{D}$ are the lift and drag coefficients of the respectively, and $c$ is the chord length of the fan blade.

The fan blade forces are scaled according to the solidity ratio, $\sigma$, of the fan:

$$
\sigma=\frac{n_{b} c}{2 \pi r}
$$


where $n_{b}$ is the number of fan blades and $r$ is the radius.

The fan blade forces defined by eqs. (2) and (3) are calculated as volumetric forces, $f$, in a cylindrical reference frame with axial, tangential and radial components:

$$
\begin{aligned}
f_{a} & =\frac{1}{2} \rho\left|U_{R}\right|^{2} \frac{\sigma}{\tau}\left(C_{L} \cos (\gamma-\alpha)-C_{D} \sin (\gamma-\alpha)\right) \\
f_{t} & =\frac{1}{2} \rho\left|U_{R}\right|^{2} \frac{\sigma}{\tau}\left(C_{L} \sin (\gamma-\alpha)+C_{D} \cos (\gamma-\alpha)\right) \\
f_{r} & =0
\end{aligned}
$$

where $\tau$ is the thickness of the actuator disk's cell layer, and $\gamma$ is the fan blade's setting angle relative to its plane of rotation. The forces are added as a source term in the momentum equation.

The lift and drag coefficients for each fan blade were obtained for various Reynolds numbers using XFoil [12]. The lift and drag coefficients are approximated using flat plate theory outside of the upper and lower stall points of the fan blade profiles.

The fan shaft power consumption, $\dot{W}$, is obtained by the following volume integral:

$$
\dot{W}=\omega \int_{V} f_{t} r d V
$$

where $\omega$ is the fan's rotational speed, and $f_{t}$ is the tangential component of the ADM's source term.

\subsection{Heat Exchanger Model}

The heat exchanger is represented using two simplified numerical models that account for its heat transfer component and its pressure drop component. The heat transfer component is modeled using the $\varepsilon$-NTU (Effectiveness Number of Transfer Units) method [1], which adds a source term to the energy equation. The heat transfer rate, $\dot{Q}$, for a given effectiveness, $\varepsilon_{N T U}$, is given by:

$$
\dot{Q}=\dot{m}_{a} c_{p a}\left(T_{v}-T_{a i}\right) \varepsilon_{N T U}
$$

where $\dot{m}_{a}$ is the air mass flow rate, $c_{p a}$ is the specific heat of the air, $T_{v}$ is the steam vapor temperature, and $T_{a i}$ is the air inlet temperature.

The pressure drop component is modeled using the Darcy-Forchheimer porosity model, which adds a source term to the momentum equation. The pressure drop gradient defined by the Darcy-Forchheimer porosity model is given by:

$$
\frac{d p}{d x}=\mu k_{d} U+\rho k_{f} \frac{U^{2}}{2}
$$

where $k_{d}$ and $k_{f}$ are the Darcy and Forchheimer coefficients, and $U$ is the flow velocity.

\section{Computational Setup}

\subsection{Computational Domain \& Mesh}

The ACC comprised of an $8 \times 8$ array of A-frame forced draft fan-units. The fan-unit schematic is shown in Figure 1 (a). Windwalls are present at the periphery of the domain. The ACC itself is located in an extended atmospheric domain as shown in Figures 2 and 3. 
a)

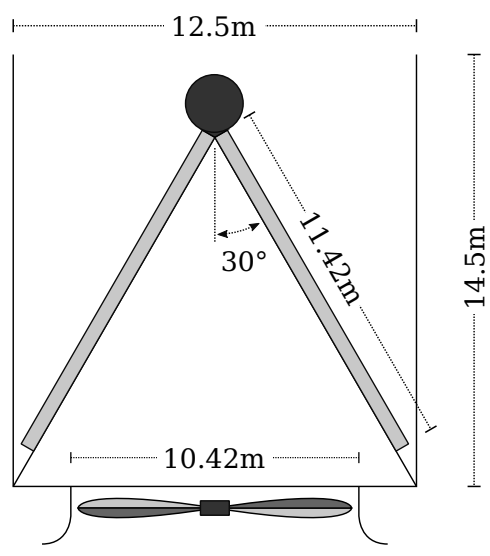

b)

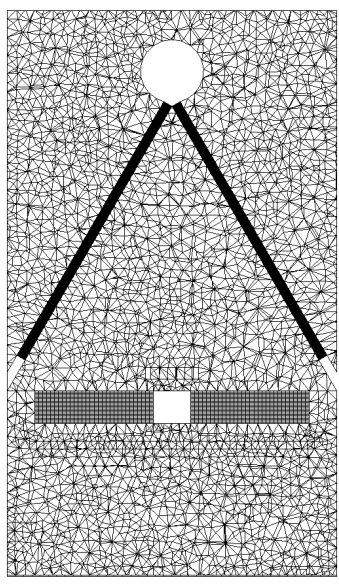

Figure 1. Single Fan-Unit: a) Domain Schematic, b) Mesh Slice

Table 1. Single Fan Forced Draft ACC Submesh Components

\begin{tabular}{lll} 
Submesh Region & Mesh Type & \\
\hline Actuator Disk & Hexahedral & Structured \\
Heat Exchanger & Hexahedral & Structured \\
Fan-Unit Lower & Tetrahedral & Unstructured \\
Fan-Unit Plenum & Tetrahedral & Unstructured \\
Fan-Unit Upper & Tetrahedral & Unstructured \\
Atmosphere & Hexahedral & Structured \\
\hline
\end{tabular}

The domain and mesh for the numerical ACC model are created in a modular fashion, which reuses a copy of the same mesh for each fan-unit. The submesh components created to form the entire computational domain are listed in Table 1

The mesh for a single fan-unit is shown in Figure 1 (b). The model used structured hexahedral cells to mesh the actuator disk region, heat exchanger region and large atmospheric region due to the regular shape of these regions, while unstructured tetrahedral cells were used to accommodate the remaining complex geometries found around the fan-unit. The final mesh for the ACC model consists of a total of $45.97 \times 10^{6}$ cells, of which $20.98 \times 10^{6}$ are hexahedral cells and $24.81 \times 10^{6}$ are tetrahedral cells.

\subsection{Axial Flow Fan Configuration}

The 64 fan-units are identified using an $(i, j)$-indexing scheme, respectively identifying the $x$ and $y$-coordinate of the fan-unit as shown in Figure 2 . The $i$-index indicates which street the fan-unit belongs to, while the $j$-index where in the street the fan-unit is located. Fan-units of the same street (shared $i$-index) share a steam duct, but each fan-unit has a seperate plenum chamber.

The ACC is configured using two different axial flow fans, namely the L-fan and the $\mathrm{N}$-fan:

1. The L-fan is located at the front, $j=1$, and the back, $j=8$, sides of the ACC, and is configured using a blade setting angle of $9.3^{\circ}$. 


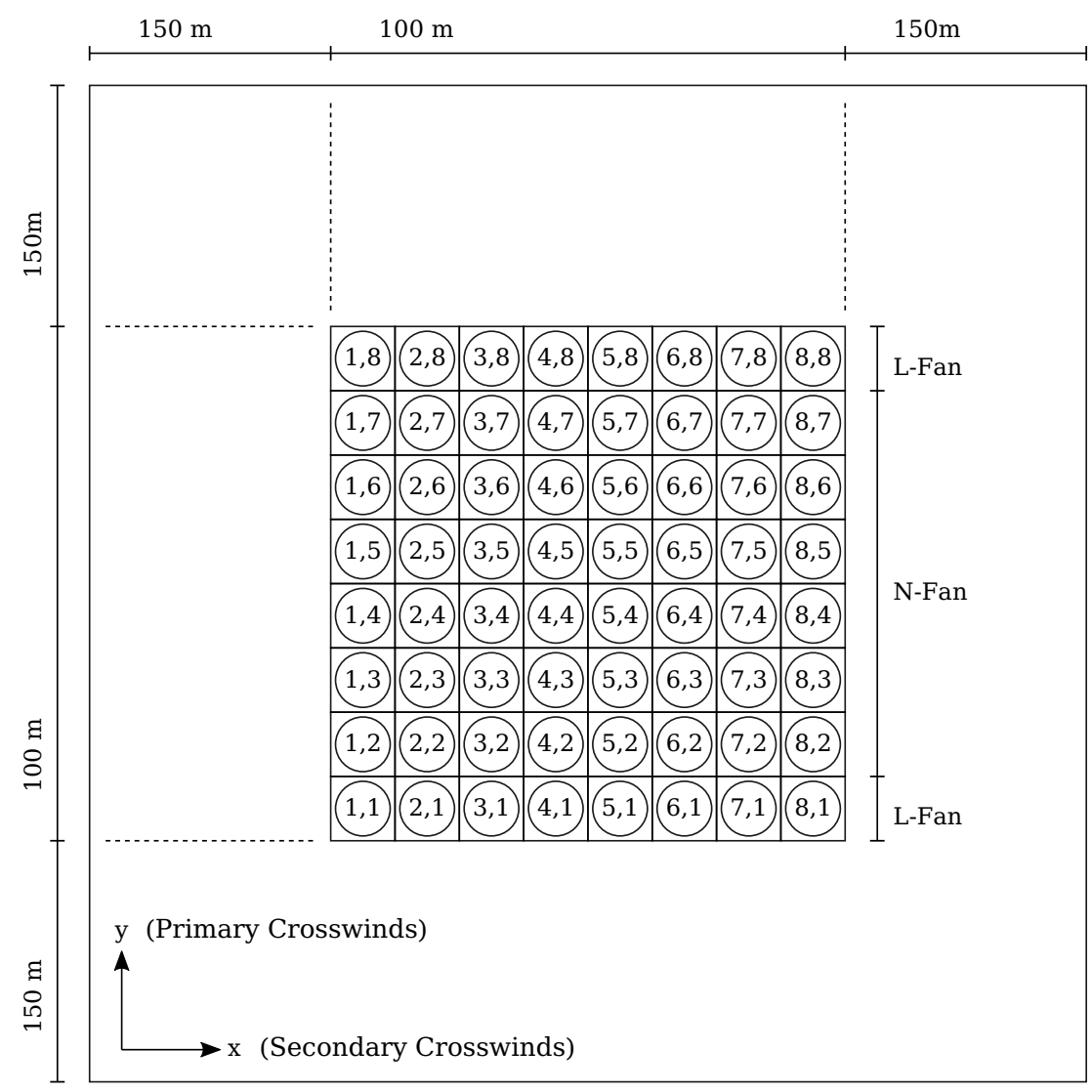

Figure 2. ACC Schematic: Top View

2. The $\mathrm{N}$-fan is used for the remainder of the fan-units, $j \in[2,7]$, and is configured using a blade setting angle of $11.6^{\circ}$.

Comparatively the L-fan has a steeper pressure characteristic curve and shaft power requirement, and the $\mathrm{N}$-fan has a flatter pressure characteristic and shaft power requirement. The use of L-fan at the front and back of the ACC is an attempt to mitigate performance losses that occur under adverse crosswinds.

\subsection{Ambient \& Boundary Conditions}

The ACC model's boundary conditions are set to match atmospheric conditions. The boundary conditions used are tabulated in Table 2 . The ambient conditions for the simulation are calculated using a reference pressure, $p_{r e f}$, of $101325 \mathrm{~Pa}$ and a reference temperature, $T_{r e f}$, of $300 \mathrm{~K}$.

A fixed value boundary condition is used to apply the crosswind's velocity profile at the appropriate atmospheric inlet boundaries of the domain using an atmospheric boundary layer (ABL) [13]. The velocity profile for a given reference velocity, $U_{r e f}$, at a given reference 


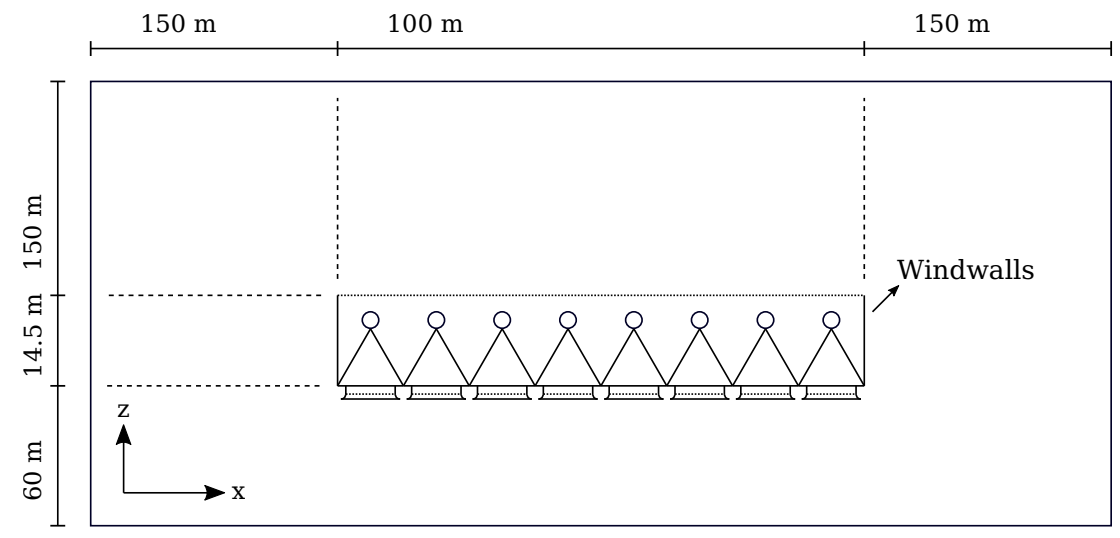

Figure 3. ACC Schematic: Front View

Table 2. Forced Draft ACC Boundary Conditions

\begin{tabular}{llll} 
Field & Boundary & Type & Value \\
\hline$p^{\prime}$ & Sides / Top & Total-Pressure & $p_{\text {ref }}$ \\
& Walls & Zero-Gradient & $\nabla p^{\prime}=0$ \\
\hline$U$ & Inlet & Fixed-Values & Equation (11) \\
& Sides & Zero-Gradient & $\nabla U=0$ \\
& Walls & No-Slip & $U=0$ \\
\hline$T$ & Sides & Fixed-Value (Inlet) / Zero-Gradient (Outlet) & $T_{\text {ref }}, \nabla T=0$ \\
& Walls & Zero-Gradient & $\nabla T=0$ \\
\hline
\end{tabular}

height, $z_{\text {ref }}$, is specified as:

$$
U=\frac{U_{r e f}}{\ln \left(\frac{Z_{r e f}+z_{0}}{z_{0}}\right)} \ln \left(\frac{z+z_{0}}{z_{0}}\right)
$$

where $z$ is the vertical coordinate, $z_{0}$ is the surface roughness (default of $0.1 \mathrm{~m}$ ), and $z_{g}$ is the minimum $z$-value.

Standard wall-functions are used for the standard $k$ - $\varepsilon$ turbulence model.

\subsection{Performance Criteria}

The following fan-unit performance criteria are defined to facilitate a comparison between the different axial flow fans used in the ACC. The volumetric effectiveness and heat transfer effectiveness respectively represent the normalised volumetric flow rate through a single fanunit and the normalised heat transfer rate for a fan-units heat exchangers.

$$
\begin{gathered}
\varepsilon_{\dot{V}}=\frac{\dot{V}}{\dot{V}_{\text {ideal }}} \\
\varepsilon_{\dot{Q}}=\frac{\dot{Q}}{\dot{Q}_{\text {ideal }}}
\end{gathered}
$$

where $V_{\text {ideal }}$ is the volumetric flow rate of an idealized single fan-unit ACC axial flow fan and $Q_{\text {ideal }}$ is the heat transfer rate of a idealized single fan-unit ACC's heat exchangers. The 
idealized volumetric flow rates and heat transfer rates were determined using an isolated single fan-unit ACC model with no crosswinds applied.

Finally, the heat-to-power ratio represents the ratio between a fan-unit's heat transfer rate and fan shaft power consumption:

$$
\eta_{H T P}=\frac{\dot{Q}}{\dot{W}}
$$

\subsection{Scope}

The numerical ACC model was solved for a total of seven different crosswind conditions. The first solution serves as the reference case for normal operation of the ACC with no crosswind applied, i.e. $U_{r e f}=0 \mathrm{~m} / \mathrm{s}$. Three crosswinds with reference velocities, $U_{r e f}$, of $3 \mathrm{~m} / \mathrm{s}, 6 \mathrm{~m} / \mathrm{s}$ and $9 \mathrm{~m} / \mathrm{s}$ were applied in both the primary $y$-direction and secondary $x$-direction.

The crosswind directions chosen facilitate a comparison of the two different axial flow fans when they are used at the leading edge of the ACC. Under primary crosswind conditions the steeper pressure gradient L-fan is located at the leading edge of the ACC, while the flatter pressure gradient $\mathrm{N}$-fan is found at the leading edge under secondary crosswind conditions (except for the corner fan-units).

\section{Results \& Discussion}

\subsection{Reference Conditions}

The ACC model was evaluated without crosswind to provide a reference case. The volumetric effectiveness and heat transfer effectiveness of the ACC are shown in Figure 4
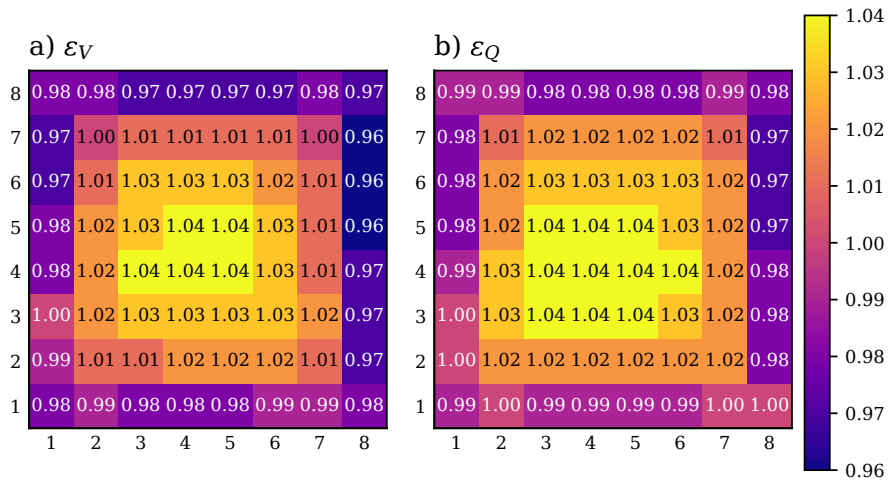

Figure 4. Reference Case: Effectiveness $\left(U_{r e f}=0 \mathrm{~m} / \mathrm{s}\right)$

Under normal operating conditions the mean volumetric effectiveness of the ACC is 1.002 and the mean heat transfer effectiveness is 1.001 . Both are shown to be slightly higher towards the center of the ACC, and slightly lower at the edges of the ACC. The increased performance at the center is attributed to airflow entering the axial flow fans at a more direct angle than at the sides of the ACC.

The mean heat-to-power ratio of the L-fan fan-units is $90.0 \mathrm{~W} / \mathrm{W}$ and the mean heat-topower ratio of the $\mathrm{N}$-fan fan-units is $102.5 \mathrm{~W} / \mathrm{W}$. The overall mean heat-to-power ratio of the ACC is $99.4 \mathrm{~W} / \mathrm{W}$. 


\subsection{Primary Crosswind Conditions}

The performance results of the ACC under the primary crosswinds of 3,6 and $9 \mathrm{~m} / \mathrm{s}$ are discussed in this section. The volumetric effectiveness is shown in Figure 5, the heat transfer effectiveness is shown in Figure 6, and the heat-to-power ratio is shown in Figure 7.
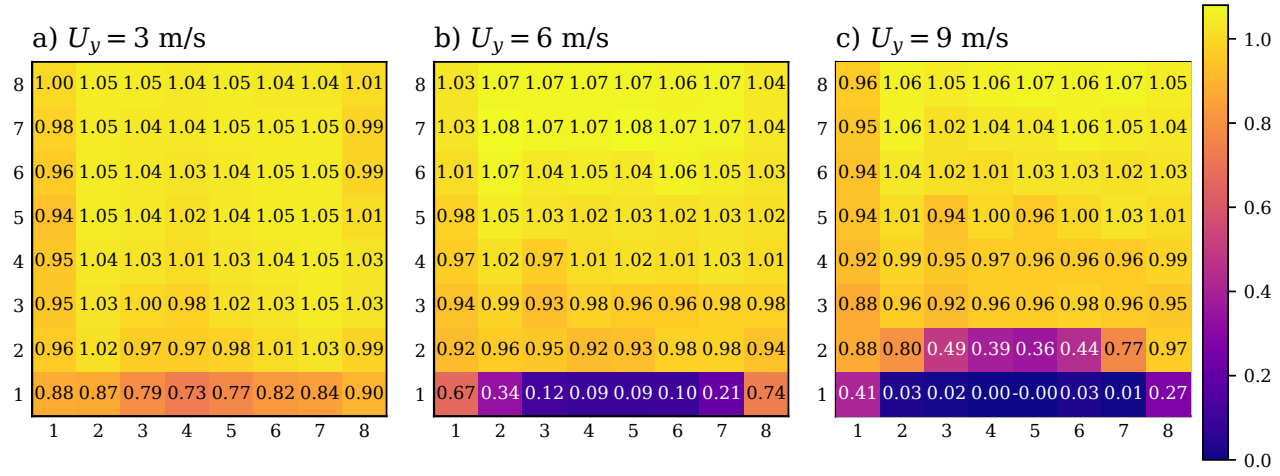

Figure 5. Volumetic Effectiveness: Primary Crosswinds ( $y$-direction)

a) $U_{y}=3 \mathrm{~m} / \mathrm{s}$

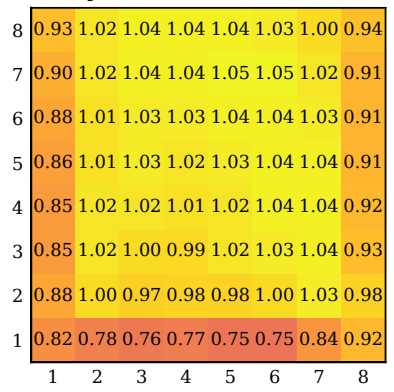

b) $U_{y}=6 \mathrm{~m} / \mathrm{s}$

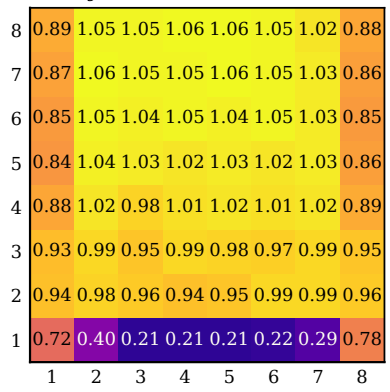

c) $U_{y}=9 \mathrm{~m} / \mathrm{s}$

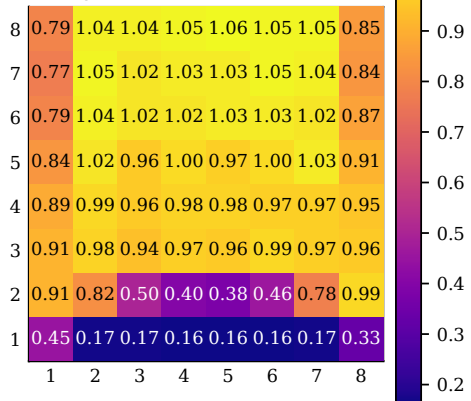

Figure 6. Heat Transfer Effectiveness: Primary Crosswinds (y-direction)

The decreases in the volumetric and heat transfer effectiveness are concentrated at the centre of the leading edge of the ACC, with smaller decreases towards the sides and downwind of the leading edge. Similar volumetric and heat transfer effectiveness were observed in previous studies of full sized ACCs [3-5].

The volumetric effectiveness of the leading edge fan-units, excluding the corner units, decreases from 0.99 under normal operating conditions to $0.80,0.16$ and 0.02 under crosswind velocities of 3,6 and $9 \mathrm{~m} / \mathrm{s}$ respectively, and comparatively the heat transfer effectiveness decreases from 0.99 to $0.78,0.26$ and 0.17 .

The fan-units directly downwind of the leading edge also exhibit decreases in volumetric and heat transfer effectiveness. The effectiveness values of the above-mentioned fan-units decrease from the norm of 1.02 to $1.00,0.95$ and 0.54 under crosswind velocities of 3,6 and $9 \mathrm{~m} / \mathrm{s}$ respectively. 

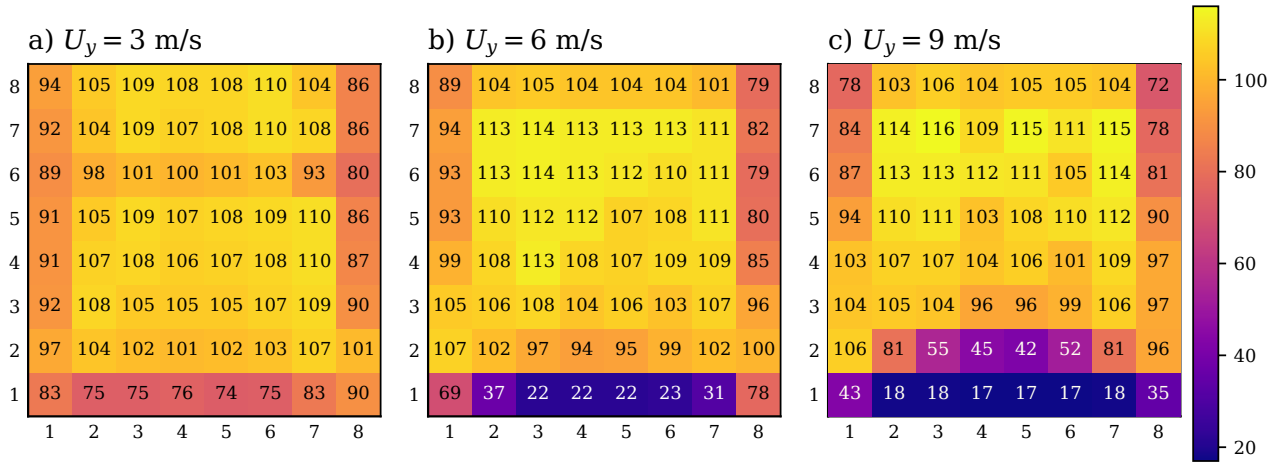

Figure 7. Heat-to-Power Ratio: Primary Crosswinds ( $y$-direction)

Under the primary crosswinds the volumetric effectiveness and heat transfer effectiveness are shown to have a very close correlation. However, the differences between the two suggests that an additional factor contributes to the decrease in heat transfer rate, e.g. increased inlet air temperatures. At the leading edge the increased heat exchanger inlet tempreatures is attributed to reverse flow throught the fan-units which allows heated air to flow from the plenum chamber into the supply flow of the downwind fan-units. At the sides of the ACC aligned with the crosswinds the increase is attributed to hot-plume recirculation where hot air exiting the heat exchangers is captured in vortices that recirculate the air into the supply flow of downwind fan-units.

The heat-to-power ratio of the leading edge fan-units, excluding the corner units, respectively decreases from $90.7 \mathrm{~W} / \mathrm{W}$ to $76.3,26.2$ and $17.5 \mathrm{~W} / \mathrm{W}$ at crosswind velocities of 3, 6 and $9 \mathrm{~m} / \mathrm{s}$. Immediately downwind of the leading edge the heat-to-power ratio decreases from 103.2 W/W under normal operating conditions and $3 \mathrm{~m} / \mathrm{s}$ crosswinds to 98.2 and $59.3 \mathrm{~W} / \mathrm{W}$ under 6 and $9 \mathrm{~m} / \mathrm{s}$ crosswinds respectively.

Some asymmetry is shown in the two effectiveness values and the heat-to-power ratios at the left and right hand sides of the ACC. The asymmetry is minimal at low crosswind velocities and is more prominent at high crosswind velocities. The asymmetry is attributed to the rotation of the fans as modeled by the ADM.

\subsection{Secondary Crosswinds Conditions}

The performance results of the ACC under the secondary crosswinds of 3,6 and $9 \mathrm{~m} / \mathrm{s}$ are discussed in this section. The volumetric effectiveness is shown in Figure 8, the heat transfer effectiveness is shown in Figure 9, and the heat-to-power ration is shown in Figure 10.

The volumetric effectiveness of the leading edge fan-units, excluding corner fan-units, decreases respectively from 0.98 under normal operating conditions to $0.37,-0.07$ and -0.16 under crosswind velocities of 3,6 and $9 \mathrm{~m} / \mathrm{s}$, and the heat transfer effectiveness decreased from 0.99 under normal operating conditions to $0.36,0.14$ and 0.10 respectively. The negative volumetric effectiveness values are indicative of reverse flow throught the fan-units.

The volumetric effectiveness of the fan-units immediately downwind of the leading edge decreases from 1.01 under normal operating conditions respectively to $1.01,0.84$ and 0.34 at crosswind velocities of 3, 6 and $9 \mathrm{~m} / \mathrm{s}$. Similar effectiveness values are seen for the heat transfer, as was the case for primary crosswind conditions. 
a) $U_{x}=3 \mathrm{~m} / \mathrm{s}$

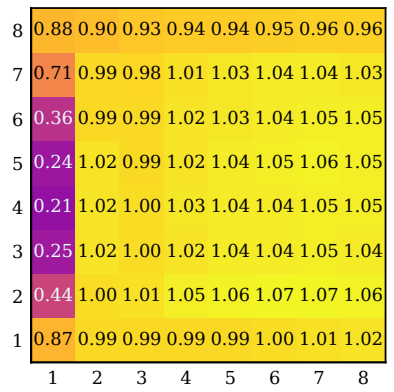

b) $U_{x}=6 \mathrm{~m} / \mathrm{s}$

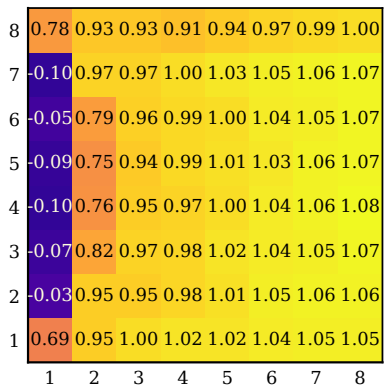

c) $U_{x}=9 \mathrm{~m} / \mathrm{s}$

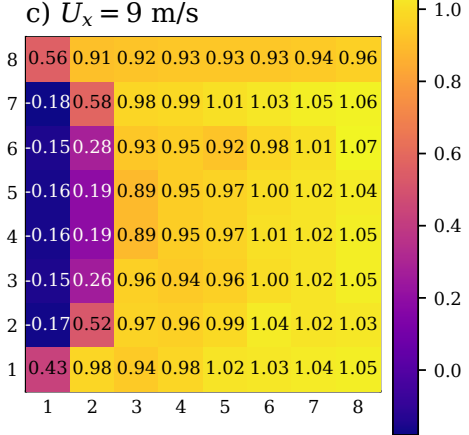

Figure 8. Volumetic Effectiveness: Secondary Crosswinds ( $y$-direction)

a) $U_{x}=3 \mathrm{~m} / \mathrm{s}$

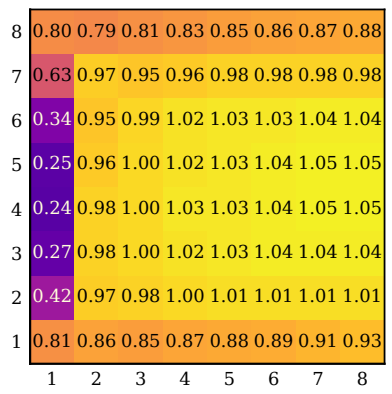

b) $U_{x}=6 \mathrm{~m} / \mathrm{s}$

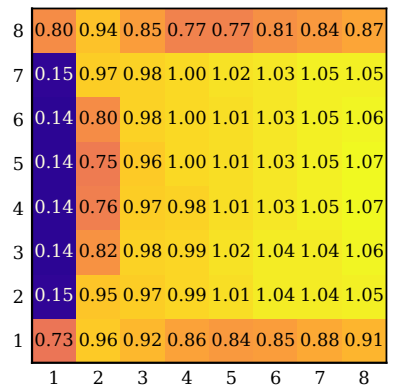

c) $U_{x}=9 \mathrm{~m} / \mathrm{s}$

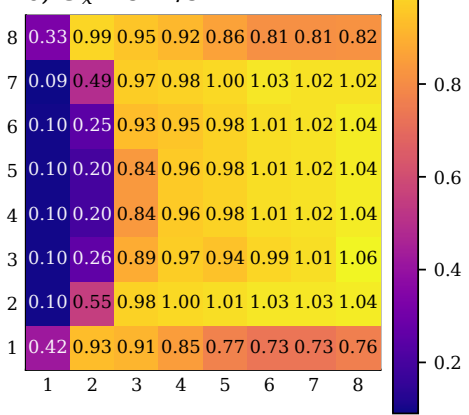

Figure 9. Heat Transfer Effectiveness: Secondary Crosswinds ( $y$-direction)

The heat-to-power ratios of the leading edge fan-units, excluding the corner fan-units, decreases from $98.2 \mathrm{~W} / \mathrm{W}$ under normal operating conditions respectively to 40.3, 18.7 and $13.3 \mathrm{~W} / \mathrm{W}$ at crosswind velocities of 3,6 and $9 \mathrm{~m} / \mathrm{s}$.

Similar to the primary crosswind cases, some asymmetry is shown in the two effectiveness values and the heat-to-power ratios at the sides of the ACC parallel to the crosswind direction.

\subsection{Comparison Between Crosswind Conditions}

A comparison of the ACC's volumetric effectiveness and heat transfer effectiveness and heatto-power ratios between the two crosswind conditions is shown in Figure 11. The comparisons are shown for the ACC as a whole (overall mean), and for the leading edge fan-units (leading edge mean) excluding the corner fan-units. The corner fan-units are excluded due to their use of the L-fan and their ability to draw air in from multiple directions preventing a fair direct comparison of reduced fan performance at the leading edge.

The volumetric effectivenesso comparison, Figure 11 (a), shows that the fan performance of the entire ACC is marginally better under primary crosswind conditions for all crosswind velocities simulated. However the volumetric effectiveness at the leading edge fanunits is significantly better under primary crosswind conditions. This phenomena is directly 
a) $U_{x}=3 \mathrm{~m} / \mathrm{s}$

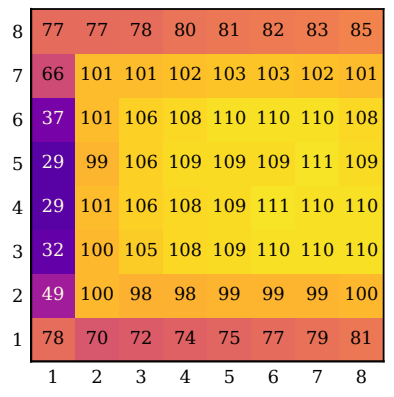

b) $U_{x}=6 \mathrm{~m} / \mathrm{s}$

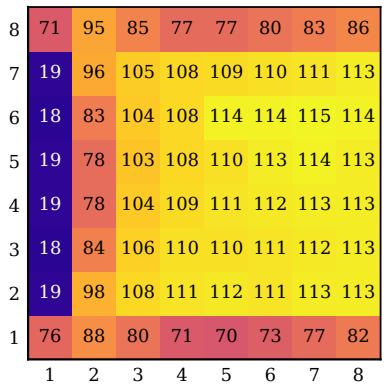

c) $U_{x}=9 \mathrm{~m} / \mathrm{s}$

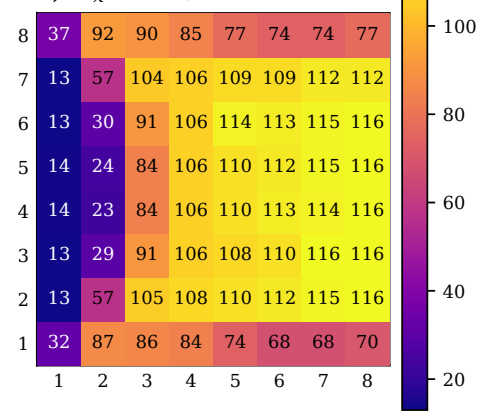

Figure 10. Heat-to-Power Ratio: Secondary Crosswinds ( $y$-direction)

a) $\varepsilon_{V}$

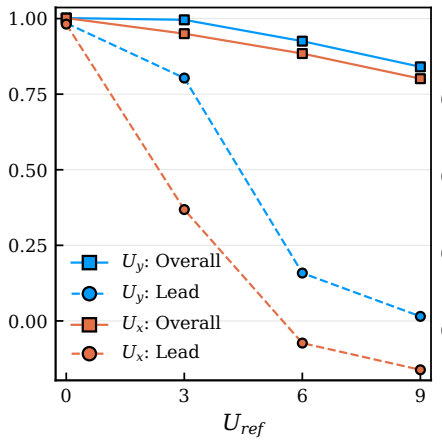

b) $\varepsilon_{Q}$

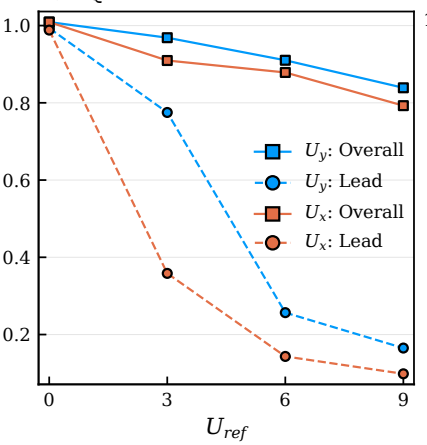

c) $\eta_{H T P}$

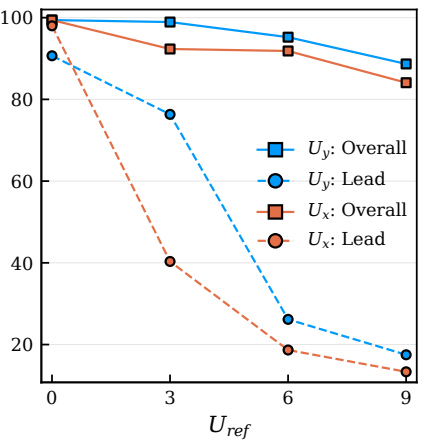

Figure 11. Comparison: a) Volumetric Effectiveness, b) Heat Transfer Effectiveness, c) Heat-to-Power Ratio

attributed to the use of the L-fan whose steeper pressure gradient is better able to mitigate the adverse effects of crosswinds at the leading edge. Similar performance trends regarding comparable fan located at the periphery of the ACC have previously been observed [5].

Similar to the volumetric effectiveness, the heat transfer effectiveness of the entire ACC, Figure 11 (b), is marginally better under all crosswind velocities, and also significantly better at the leading edge of the ACC. The volumetric effectiveness is also seen to be correlated with the heat transfer effectiveness with both effectiveness values showing similar overall trends and trends at the leading edge.

Finally the heat-to-power ratio comparison, Figure 11 (c), shows similar trends to the volumetric and heat transfer effectiveness with higher heat-to-power ratios for the entire ACC under primary crosswind conditions. It is also noted that under primary crosswinds, and despite a lower heat-to-power ratio at the leading edge, the L-fan is shown to be less susceptible to a decrease in the heat-to-power ratio as the crosswind velocity increases. This suggests that the use of the L-fan at the leading edge is an appropriate design choice to mitigate any expected adverse fan performance due to crosswinds. 


\section{Conclusions}

The actuator disk model was used to model the two types of axial flow fans of a large ACC under adverse crosswinds conditions. The model was able to capture the asymmetrical flow field phenomenon under crosswind conditions and directly calculate the axial flow fan's power consumption.

The volumetric effectiveness of the ACC was found to correlate with the heat transfer effectiveness. This indicates that the primary cause of reduced ACC performance under crosswind conditions is a reduction in the axial flow fan's performance. Secondary causes such as increased heat exchanger inlet air temperatures were identified, but their effect on the ACC's performance is significantly less.

The fan-units affected by the crosswinds were found at the leading edge of the ACC. Consequently the ACC performed much better under primary crosswinds than under secondary crosswinds due to the use of the L-fan at the leading edge fan units. The L-fan's steeper pressure gradient able to mitigate the adverse fan performance at the leading edge much better than the N-fan.

\section{References}

[1] D.G. Kröger, Air-cooled Heat Exchangers and Cooling Towers (Departement of Mechanical Engineering University Stellenbosch, Stellenbosch, South Africa, 1998)

[2] J. Bredell, D. Kröger, G. Thiart, Applied Thermal Engineering 26, 846 (2006)

[3] M.T.F. Owen, D.G. Kröger, Journal of Engineering for Gas Turbines and Power 133 (2011)

[4] F.G. Louw, Master's thesis, University of Stellenbosch (2011)

[5] R.A. Engelbrecht, J. van der Spuy, C.J. Meyer, A. Zapke, Numerical Investigation of the Performance of a Forced Draft Air-Cooled Heat Exchanger (2017), Vol. Volume 5A: Heat Transfer of Turbo Expo: Power for Land, Sea, and Air

[6] S.J. van der Spuy, T.W. von Backström, D.G. Kröger, R \& D Journal of the South African Institute of Mechanical Engineers 26, 12 (2009), revised 2010

[7] G.D. Thiart, T.W. von Backström, Journal of Wind Engineering and Industrial Aerodynamics 45, 189 (1993)

[8] H.K. Versteeg, W. Malalasekera, Introduction to Computational Fluid Dynamics: The Finite Volume Method, 5th edn. (McGraw-Hill Education, New York, NY, 2015)

[9] M.T. Schobeiri, Fluid Mechanics for Engineers (Springer, Berlin, Heidelberg, 2010)

[10] B.E. Launder, D.B. Spalding, Computer Methods in Applied Mechanics and Engineering (1974)

[11] The OpenFOAM FOUNDATION (2021), https: //openfoam.org

[12] M. Drela, Low Reynolds Number Aerodynamics (1989)

[13] D.M. Hargreaves, N.G. Wright, Journal of Wind Engineering and Industrial Aerodynamics 95, 355 (2007) 